\title{
Analyzing the Impacts of Urbanization and Seasonal Variation on Land Surface Temperature Based on Subpixel Fractional Covers Using Landsat Images
}

\author{
Youshui Zhang, Heiko Balzter, Bin Liu, and Yajun Chen
}

\begin{abstract}
Impervious surface areas (ISAs) and vegetation are two major urban land cover types. Estimating the spatial distribution of ISA and vegetation is critical for analyzing urban landscape patterns and their impact on the thermal environment. In this paper, linear spectral mixture analysis (LSMA) is used to extract their respective subpixel land cover composition from bitemporal Landsat images and the accuracy of the fractional covers is assessed with a subpixel confusion matrix at the category level and the map level by comparing with the reference data from high-resolution images. The percent ISA was divided into discrete categories representing different urban development density areas. Mean land surface temperature (LST) is calculated for each ISA category to analyze the thermal characteristics of different levels of development in the urban area of Fuzhou, China. ISA and vegetation variations are also quantified between different ISA categories and different dates. The contribution index is also calculated based on each ISA category to analyze the impact of different landscape patterns on the urban thermal environment. The results show that ISA category is an important determinant of the urban thermal environment. Furthermore, seasonal variations significantly impact the strength of this relationship. In the study area, the contribution indices were highest in the $90 \%-100 \%$ ISA category in summer 2013 and early spring 2001. The analytical methodologies used in this study can help to quantify urban thermal environmental functions under conditions of urban expansion and explore the climate adaptation potential of cities.
\end{abstract}

Index Terms-Contribution index (CI), fractional vegetation cover (FVC), land surface temperature (LST), linear spectral unmixing, percent impervious surface area (ISA), subpixel confusion matrix, urban heat island (UHI).

\section{INTRODUCTION}

$\mathbf{T}$ HE change from nonurban land cover (pervious surfaces such as grass, forest, water body, crop field, etc.) and to

Manuscript received April 28, 2016; revised July 19, 2016; accepted August 10, 2016. Date of publication November 27, 2016; date of current version March 22, 2017. The work of H. Balzter was supported by the Royal Society Wolfson Research Merit Award, 2011/R3 and the NERC National Centre for Earth Observation.

Y. Zhang, B. Liu, and Y. Chen are with the College of Geography, Fujian Normal University, Fuzhou 350007, China, and also with the State Key Laboratory of Subtropical Mountain EcologyFujian Normal University, Fuzhou 350007, China (e-mail: zhangyoushui @ sina.com; liubin561 @ sina.cn; 1433105756@qq.com).

H. Balzter is with the Department of Geography, Leicester Institute for Space and Earth Observation, Centre for Landscape and Climate Research, University of Leicester, Leicester, LE1 7RH, U.K., and also with the National Centre for Earth Observation, University of Leicester, Leicester, LE1 7RH, U.K. (e-mail hb91@le.ac.uk).

Color versions of one or more of the figures in this paper are available online at http://ieeexplore.iee.org.

Digital Object Identifier 10.1109/JSTARS.2016.2608390 urban land cover (such as impervious surfaces) can result in significant environmental impacts in cities including locally increased land surface temperature (LST), reduced evapotranspiration, more surface runoff, increased storage and transfer of sensible heat, and deterioration of air quality [1], [2]. These changes have a significant influence on human health and the urban environment [3], [4]. LST change is a key area of urban climate research [5], [6]. The relationship between the LST and urban landscape patterns is the focus of many studies of the urban heat island (UHI) effect [7]-[9]. Therefore, the impacts of the changes of urban impervious surfaces and vegetation, on the variability of the urban thermal environment in different seasons needs to be investigated in order to mitigate the UHI effect and adapt effectively to climate change.

With the advance of remote sensing technology, it is possible to study urban thermal environments using satellite remote sensing data. Images from the Landsat series are often used to detect spatiotemporal variations of urban impervious surface, vegetation, and LST [10], [11]. To mitigate the UHI effect and adapt urban areas to climate change, we need to know how changes in impervious surface area (ISA) and vegetation cover contribute to urban LST. Per-pixel classifiers cannot handle heterogeneous urban landscapes effectively at the Landsat resolution because of the mixed-pixel problem [12]. This hampers an accurate analysis of the often fine-scale spatial structure of urban landscapes and its thermal characteristics. Subpixel approaches provide a good way to characterize the heterogeneity present in urban landscape patterns [13]-[15]. Subpixel fractional cover types, such as percent ISA and fractional vegetation cover (FVC), can be used to characterize urban land cover patterns in more detail [16], [17]. Percent ISA and FVC can provide complementary metrics to the traditionally applied land cover types for urban thermal environment analysis [8]. The vegetation-impervioussoil (VIS) model addresses the mixed-pixel problem in urban area [18]-[20]. Continuous percent ISA information can reveal areas of urban development with varying densities and patterns [11]. Linear spectral mixture (LSM) models are often used to extract the subpixel impervious surface, vegetation, and soil.

Accuracy assessments of hard classifications commonly use an error matrix or confusion matrix [21]. It quantifies the agreement between the reference data and the classified map [22]. In the error matrix, some descriptive and analytical statistical techniques such as overall accuracy (OA), user's accuracy (UA) and producer's accuracy (PA), and kappa coefficient 
of agreement $(\kappa)$ are commonly used to assess the accuracy. Soft classifiers based on spectral unmixing analysis, probability theory, artificial neural networks, expert systems, and decision tree regression are increasingly being used [23]. However, methods for accuracy assessment of subpixel fractional cover from soft classification are still under development [22]. Methods for subpixel land cover types generally involve scatterplots of predicted versus observed values, correlation analysis, bias estimation, root-mean-square error, etc. Here, we use a subconfusion matrix to assess the accuracy of subpixel fractional covers derived from spectral unmixing.

Many studies analyzed the impact of urban land cover change on LST [24], [25]. Percent ISA and FVC have been used to analyze the spatiotemporal patterns of LST [4], [8], [11], [17], [26], [27], and the results of these studies have shown that percent ISA and FVC provide complementary information to hard classified land cover types. However, based on percent ISA categories of areas with varying densities, the effects of composition of urban ISA and green spaces on LST are not well understood. Therefore, based on different ISA categories, the variations of fractional covers of ISA and vegetation area on LST need to be measured to analyze the impact of variations of urban development density on the urban thermal environment.

In this study, we selected Fuzhou city in Eastern China as the study area. Linear spectral mixture analysis (LSMA) was used to extract subpixel fractional cover data from the two periods, and a subconfusion matrix was used to analyze the accuracy of the extracted fractional covers by comparing with reference data. Urban thermal patterns were analyzed by mean percent ISA, mean FVC and mean LST based on different ISA categories.

The aim of this study was to analyze the spatiotemporal patterns of urban landscapes and their influence on urban LST, and the contributions of different ISA categories to the urban thermal environment. The intended impact of the research is to help the city in adapting effectively to climate change impacts on urban thermal environments.

\section{StUdy AREA AND DATA}

Fuzhou City is located on the southeastern coast of China (see Fig. 1). The population of Fuzhou is rapidly increasing (from 6.5 million in 2001 to 7.1 million in 2013) leading to rapid urban expansion. Driven by fast economic growth and population increase, Fuzhou has experienced rapid urbanization in the past 30 years, along with a drastic transformation of the urban landscape patterns and environment. The city has a subtropical humid climate, and the vegetation cover in the region is predominantly evergreen and the FVC is almost invariable in different seasons. Compared with the hot summer climate, the weather of Fuzhou in spring, autumn and winter are relatively cool and the weather variations between spring, autumn and winter are not as large. Therefore, bitemporal images, a Landsat 7ETM+ image (acquired on March 4, 2001), and a Landsat 8 Operational Land Imager (OLI) and thermal infrared sensor (TIRS) images (acquired on August 4, 2013) were selected to quantify the seasonal distributions of urban landscape patterns and LST for the two major characteristic climatic seasons. The bands 1-5 and 7 of ETM+ image have a spatial resolution of $30 \mathrm{~m}$, and the thermal infrared band (band 6) has $60 \mathrm{~m}$ for ETM + . The bands $1-7$ of OLI have a spatial resolution of $30 \mathrm{~m}$, while 100 $\mathrm{m}$ for the thermal infrared bands (bands 10 and 11) for TIRS.

An IKONOS multispectral image (acquired on October 29, 2000) with $4 \mathrm{~m}$ spatial resolution and a Chinese ZY-3 multispectral image (acquired on March 4,2013) with $5.8 \mathrm{~m}$ spatial resolution were used as ancillary data to analyze the urban land cover patterns and accuracy assessment. The IKONOS and ZY-3 images were reprojected to the Universal Transverse Mercator (UTM) projection. The seasonal ETM+/OLI/TIRS images were also georeferenced to a common UTM coordinate system based on the geocoded IKONOS and ZY-3 images. The RMSE of the georectification was $<0.3$ pixels $(<9 \mathrm{~m})$. Using the atmospheric correction method of the FLAASH package in ENVI, the visible and near-infrared bands of ETM+/OLI images were converted to land surface reflectance.

\section{Methodology}

The methodology for this study consists of four steps. Step 1 includes LST retrieval and fractional covers retrieval using LSMA. Step 2 includes accuracy assessment of subpixel fractional covers with a subconfusion matrix, and then fractional cover change analysis for each ISA category. Step 3 analyzes the bitemporal relationships between mean LST, FVC, and percent ISA based on different ISA categories related to urban development density. Step 4 explores the contributions of each ISA category to the regional thermal environment. To demonstrate the process of the study, a flowchart is illustrated in Fig. 2.

\section{A. Landsat LST Retrieval}

The radiative transfer equation was used to retrieve LST from the Landsat data. This method has three steps [11], [27], [28]: Step 1 is to convert the digital numbers of thermal bands to topof-atmosphere (TOA) radiance using the following formula, for the Landsat 7 ETM+ image:

$$
\begin{aligned}
L_{\lambda}= & {\left[\left(L_{\max }-L_{\text {min }}\right) /\left(Q_{\mathrm{cal}_{\text {max }}}-Q_{\mathrm{cal}_{\text {min }}}\right)\right] } \\
& \times\left(Q_{\text {cal }}-Q_{\mathrm{cal}_{\text {min }}}\right)+L_{\text {min }}
\end{aligned}
$$

where $L_{\lambda}$ is the TOA radiance image of the thermal band, $L_{\max }=17.04 \mathrm{~W} /\left(\mathrm{m}^{2} \mathrm{sr} \mu \mathrm{m}\right), L_{\min }=0, \mathrm{Q}_{\mathrm{cal}_{\mathrm{min}}}=1$, and $Q_{\mathrm{cal}_{\max }}=255, \mathrm{Q}_{\mathrm{cal}}$ is the pixel digital number for thermal band 6 . Similar to (1), for Landsat 8 TIRS images, TIRS band data can be converted to TOA spectral radiance as

$$
L_{\lambda}=M_{L} Q_{\text {cal }}+A_{L}
$$

where $M_{L}$ is the band-specific multiplicative rescaling factor and $A_{L}$ is the band-specific additive rescaling factor. $M_{L}$ and $A_{L}$ are provided in the metadata file of the Landsat 8 data. $L_{\lambda}$ and $Q_{\text {cal }}$ in (2) are the same as those in (1).

Step 2 is to convert TOA radiance of the thermal band to surface-leaving radiance using the atmospheric correction tool MODTRAN 4.1 to remove the effects of the atmosphere [29]. The surface-leaving radiance $L_{\mathrm{T}}$ is calculated as follows [30]:

$$
L_{T}=\left(L_{\lambda}-L_{\mu}-\tau(1-\varepsilon) L_{d}\right) / \tau \varepsilon
$$



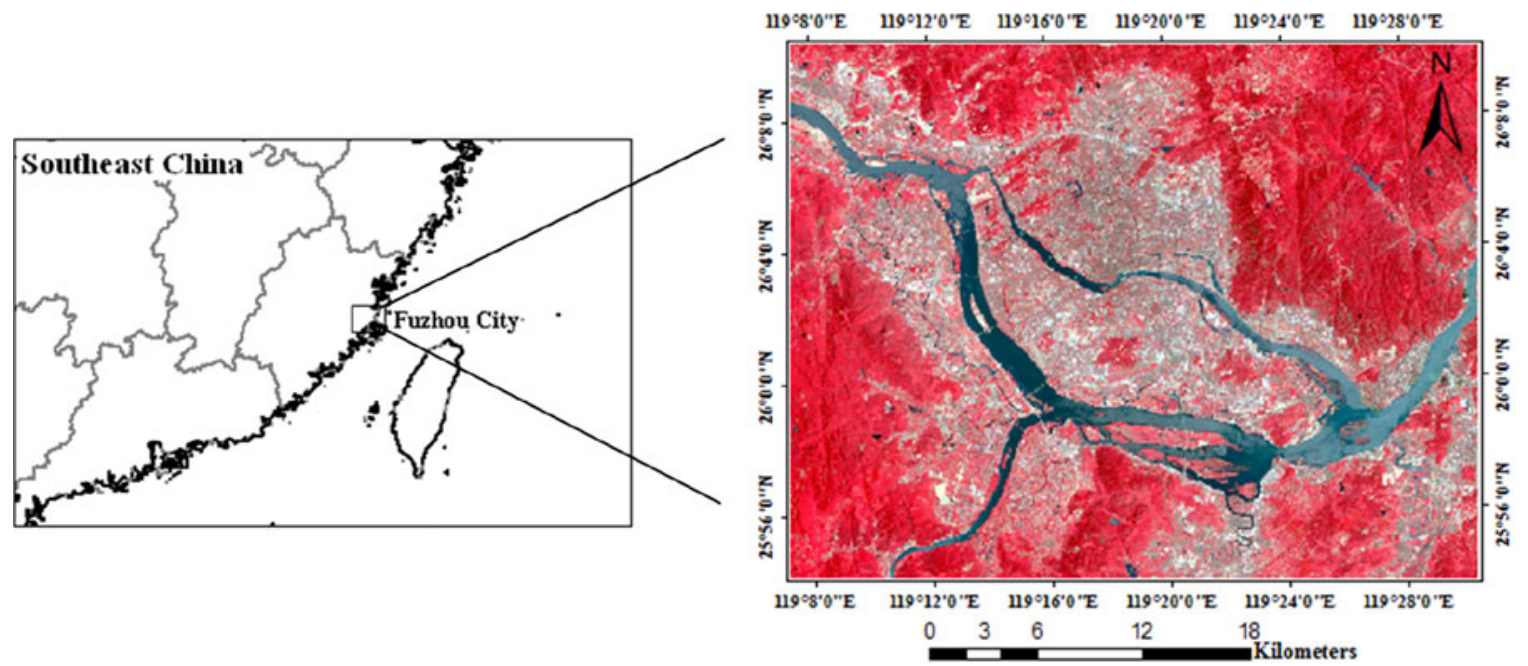

Fig. 1. Location of the study area (left) and the Landsat 8 OLI image shown in RGB (right).

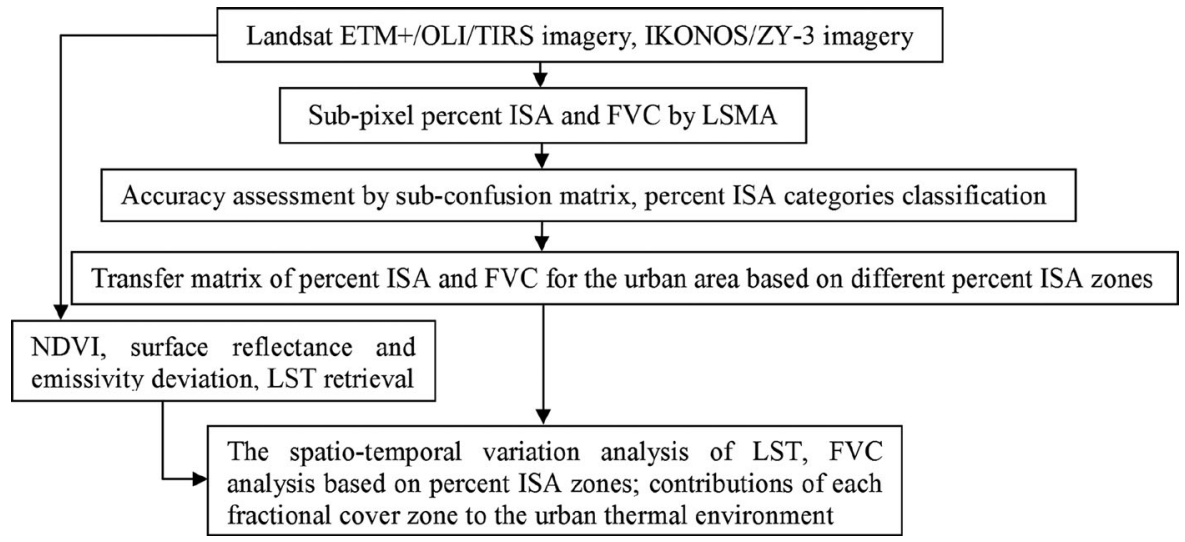

Fig. 2. Flowchart showing the steps in the study.

where $L_{\mu}, \tau$, and $L_{d}$ are, respectively, the upwelling radiance, atmospheric transmission, and downwelling radiance. $\varepsilon$ is the emissivity of the surface related to the target type. $\varepsilon$ can be calculated based on the normalized difference vegetation index (NDVI) and land cover types [31], [32]. Therefore, $\varepsilon$ is the emissivity map of the surface with $30 \mathrm{~m}$ resolution. In (3), $L_{\mu}, L_{d}$, and $\tau$ are scalars. Therefore, (3) is also a process of merging $L_{\lambda}$ and $\varepsilon$ maps, and the resolution of $L_{T}$ is $30 \mathrm{~m}$ whatever $L_{T}$ is calculated on ETM+ band 6/TIRS bands 10 and 11. Because the acquisition date of ETM+/TIRS is after January 2000, the thermal band atmospheric correction using MODTRAN is available at http://atmcorr.gsfc.nasa.gov/.

In the final step, the radiance is converted to LST using the Landsat-specific estimate of the Planck curve as follows [33]:

$$
\operatorname{LST}=\frac{k_{2}}{\ln \left[\left(k_{1} / L_{T}\right)+1\right]}
$$

where LST is the temperature in Kelvin $(K)$ and $K_{1}$ and $K_{2}$ are the prelaunch calibration constants. In this study, $K_{1}$ and $K_{2}$ are listed in Table I.

The product information for Landsat 8 at the website http://landsat.usgs.gov/Landsat8_Using_Product.php on November 14, 2013, states the larger uncertainty in the band 11
TABLE I

CALIBRATION CONSTANTS $K_{1}$ AND $K_{2}$ FOR LANDSAT ETM+/TIRS DATA

\begin{tabular}{lccc}
\hline \hline & Landsat 7 ETM+ & Landsat 8 Band 10 & Landsat 8 Band 11 \\
\hline$K_{1}$ & $666.09 \mathrm{~W} /(\mathrm{m} 2 \mathrm{sr} \mu \mathrm{m})$ & $774.89 \mathrm{~W} /(\mathrm{m} 2 \mathrm{sr} \mu \mathrm{m})$ & $480.89 \mathrm{~W} /(\mathrm{m} 2 \mathrm{sr} \mu \mathrm{m})$ \\
$K_{2}$ & $128.71 \mathrm{~K}$ & $1321.08 \mathrm{~K}$ & $1201.14 \mathrm{~K}$ \\
\hline \hline
\end{tabular}

values and recommends using band 10 data to retrieve LST. Therefore, in this study, in order to derive LST accurately, a single spectral band TIRS band 10 data was used to retrieve LST as that of the LST retrieval of the band 6 of Landsat 7 ETM+. Fig. 3 shows the LST of the study area in the imagery obtained in 2001 and 2013.

\section{B. Spectral Unmixing}

The subpixel technique of LSMA can be used to extract fractional land cover values from ETM+/OLI imagery. The LSMA approach assumes that the reflectance of every pixel at each spectral band is a linear combination of the reflectance of all endmembers within the pixel and that the spectral proportions of the endmembers represent proportions of the area [34]-[36]. 


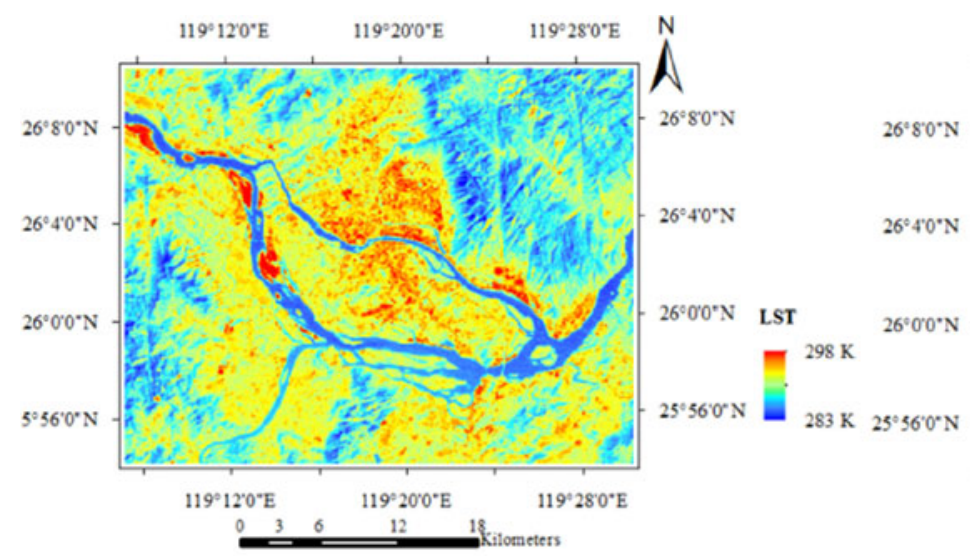

(a)

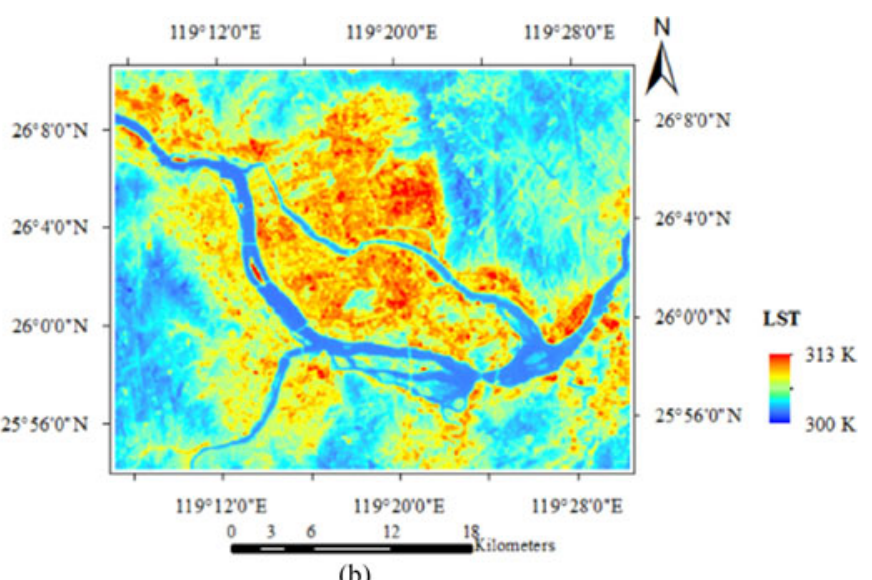

(b)

Fig. 3. LST retrieved from the (a) ETM+ image acquired on March 4, 2001, and (b) TIRS image acquired on August 4, 2013.

The spectral reflectance in band $i$ can be described as

$$
R i=\sum_{k=1}^{n} f i R i k+\varepsilon_{i}
$$

where $n$ is the number of endmembers, $f_{k}$ the fraction of endmember $k$ within the pixel, $R_{i k}$ the reflectance of endmember $k$ in band $i$, and $\varepsilon_{i}$ is the residual error for band $i$. The fractions of one pixel must sum to 1 and all fractions must be $\geq 0$. These conditions are described by

$$
\sum_{k=1}^{n} f k=1, \quad f_{k} \geq 0 \quad \text { for } k=1, \ldots, n .
$$

Applying a least squares technique, the fractional cover of each component can be estimated by (5) and (6).

Accurate endmember selection is crucial for the success of the LSMA for extracting fractional covers [37], [38]. As the purest pixels in the image, image endmembers can be derived from the extremes of the image feature space by visualization technique. More endmembers can explain more spectral variation and increase model fitness. However, too many endmembers make the mixture model sensitive to endmember selection and may not be generally applicable [39]. As the VIS model suggests, the urban environment can be assumed to consist of four components: water, vegetation, impervious surfaces, and soil [40]. Because the water endmember is not directly relevant to urban land cover composition and the spectra of water are similar to those of low-albedo ISA, The water surfaces were masked out from the images based on visual interpretation before spectral unmixing.

There are two main methods to select endmembers for spectral unmixing, namely, reference endmembers measured in a laboratory or in field conditions and image endmembers derived from the image itself [41]. In this study, ground cover spectra were not available. Thus, image endmembers were derived from the imagery. A variety of methods are used to determine endmembers from the image itself [42], [43]. Here, image endmembers were derived by the pixel purity index (PPI) and the extremes of the image feature space. A minimum noise fraction (MNF) transformation was initially applied to the imagery to reduce inherent noise. In applying the PPI analysis to MNF output to rank the pixels based on relative purity and spectral extremity, the PPI was computed by repeatedly projecting $n$-dimension scatterplots on a random unit vector and the algorithm records the extreme pixels in each projection and the total number of times that each pixel was marked as extreme. By setting a PPI threshold, the region of interest (ROI) of pure pixels was determined. Within this ROI, endmember classes were selected by choosing pixels at the edges of the point cloud in three-dimensional scatterplots of the first three bands as pure pixels. All LSMA procedures were undertaken in ENVI 4.5.

The spectral response of the impervious component in the urban environment varied widely. The analytical results of [39] showed an analysis of relationships between impervious surfaces and endmembers that impervious surfaces are likely located on or near the line connecting the low-albedo and high-albedo endmembers in the feature space diagram, and impervious surfaces can be represented by high or low-albedo endmembers. In this study, four endmembers were defined: vegetation, high-albedo impervious surfaces (such as concrete), low-albedo impervious surfaces (such as asphalt), and soil. With the LSMA model, a constrained least-squares solution was applied to spectrally unmix to get four fractional maps. The highalbedo and low-albedo ISA were summed to an image of total percent impervious surface. The fraction images for vegetation, ISA and soil in two dates were generated, as shown in Fig. 4. In Fig. 4(a), the sample plots delineated with "+" represent test sites for accuracy assessment, and the same location plots were also used for accuracy assessment for Fig 4(b)-(f). Although the high-albedo fractional ISA also included some fractional bare soil areas, bare soil areas [see Fig. 4(c) and (f)] are mainly distributed alongside the river and, therefore, do not have a significant effect on the estimation of the percent ISA. The fractional cover maps provide a measure of the physical properties of the urban land cover types at different dates, thereby helping reveal the subpixel changing patterns of urban land cover composition. 


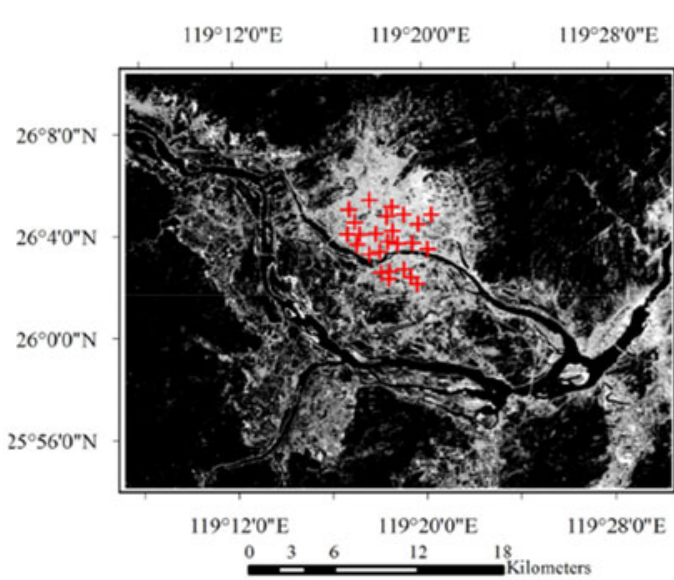

(a)

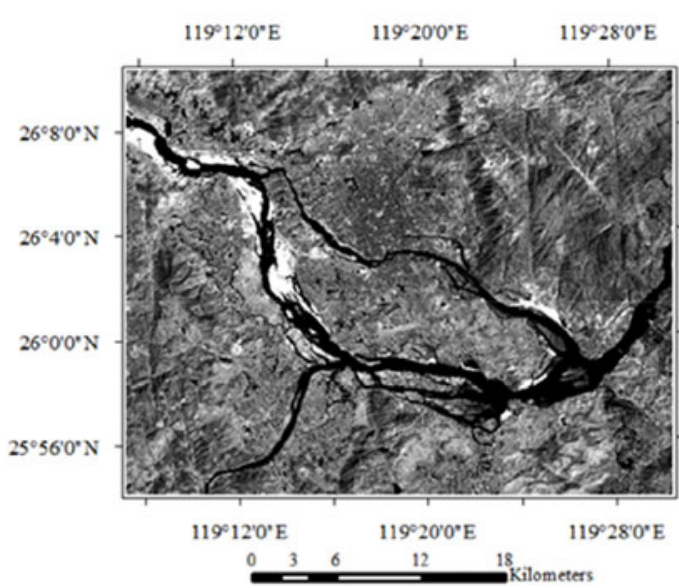

(c)

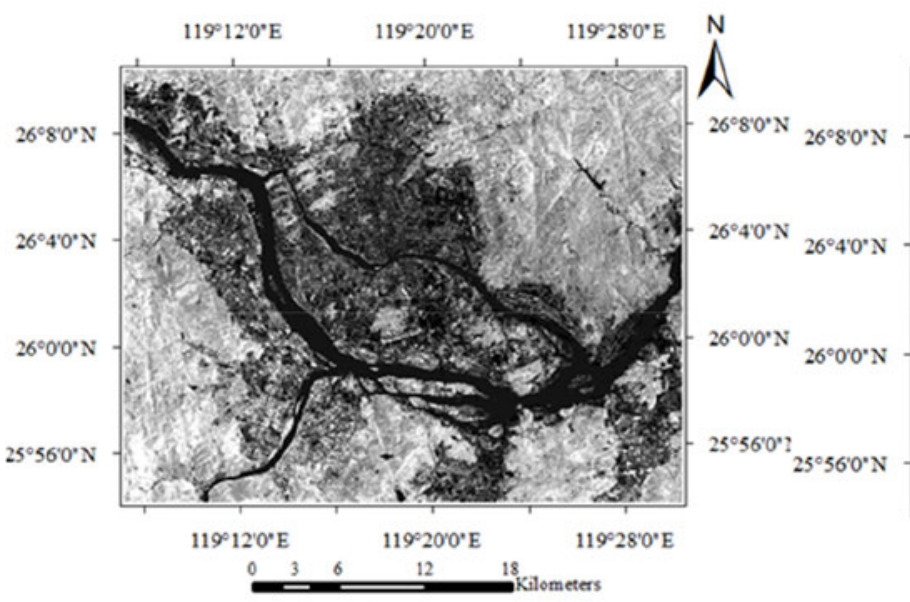

(e)
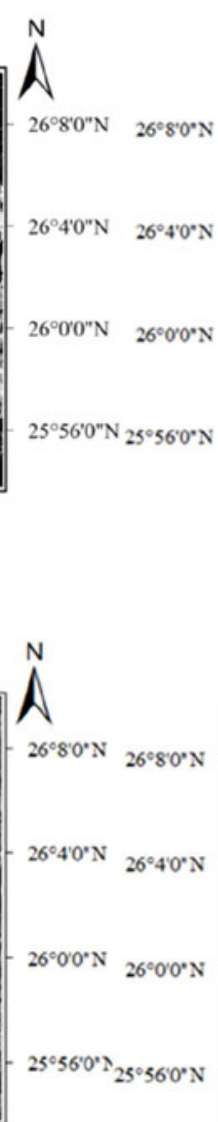

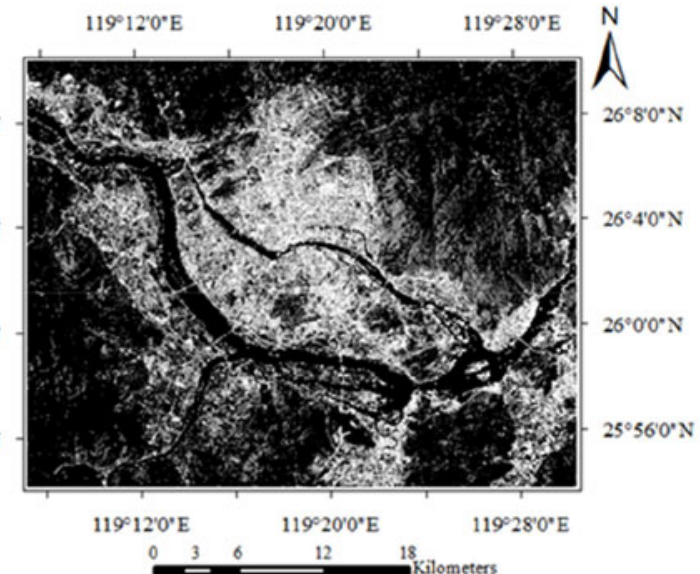

(d)

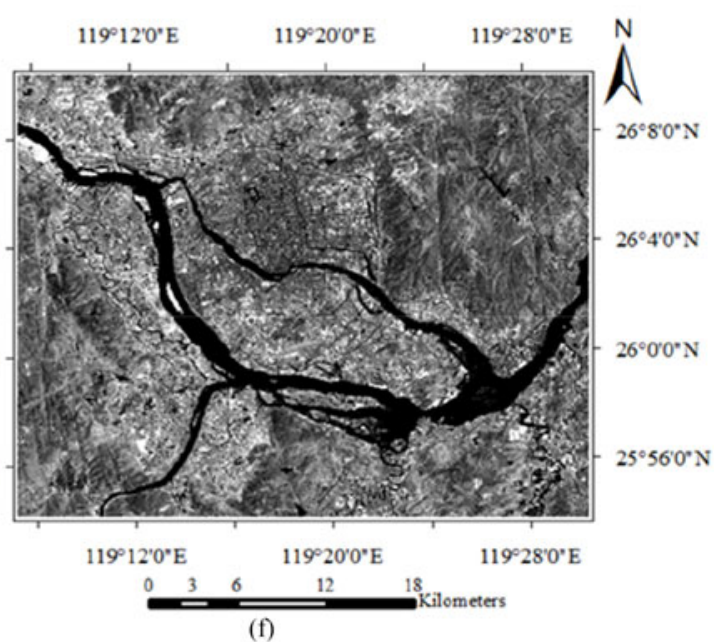

$100 \%$

Fig. 4. Fraction cover images generated from the LSMA model in 2001 and 2013: (a) fractional impervious surface in 2001; (b) fractional vegetation in 2001; (c) fractional soil in 2001; (d) fractional impervious surface in 2013; (e) fractional vegetation in 2013; (f) fractional soil in 2013.

\section{Accuracy Assessment With a Subconfusion Matrix}

In this study, the accuracy of fractional covers derived from ETM+/OLI imagery by LSMA was, respectively, assessed by comparing the fraction estimates in selected test areas with the reference data extracted from the high-resolution IKONOS (with $4 \mathrm{~m}$ spatial resolution) and ZY-3 (with $5.8 \mathrm{~m}$ spatial resolution) imagery. A subconfusion matrix was used to assess the accuracy subpixel fractional covers by comparing the fraction covers derived by LSMA with corresponding reference data derived from the high-resolution IKONOS and ZY-3 imagery. 
The iterative self-organizing data analysis technique (ISODATA) was used to extract land cover types from the IKONOS and ZY-3 imagery, respectively, and further to select test areas as reference data. This approach was feasible because the two dates in which the IKONOS and ZY-3 imagery acquired were nearly the same date as the corresponding ETM+/OLI imagery acquired, in which the land cover nearly did not change between the two dates. A set of 25 sampled data were selected as reference data to assess the accuracy of the subpixel fractional covers derived from ETM+/OLI imagery by LSMA. The ISA and vegetation extracted from high-resolution reference imagery were converted to the percentage cover of ISA and vegetation at $30 \times 30 \mathrm{~m}^{2}$ blocks and the reference data of high-resolution IKONOS and ZY-3 imagery were matched to the position of the corresponding pixels of ETM+/OLI data. The sample areas labeled as "+" in Fig. 4 show the locations of the field sites.

The conventional error matrix method is rarely used in accuracy assessment for soft classifications, because each pixel in a subpixel map has partial simultaneous membership of several classes, which overrides the assumption in the error matrix method for accuracy assessment of hard classification that a pixel belongs only to a single class [44]-[46]. In this study, the subpixel confusion matrix (SCM) for soft classification is used to assess the accuracy of the derived fraction covers by LSMA. Some statistical indices such as oa, $\kappa$, UA, and PA are calculated in the subpixel confusion matrix based on fractional values of different land covers. As with the error matrix for hard classifications, there are also two steps to calculate the SCM. The first step is to calculate the agreement of each class for diagonal elements according to the minimum rule [when $i=j$, (7)], because the agreement cannot be more than the minimum value of the two proportions. The second step is to calculate the disagreement between each class for off-diagonal elements according to (7) (when $i \neq j$ )

$$
P_{n i j}=\left\{\begin{array}{cc}
\min \left(c_{n i}, r_{n j}\right), & i=j \\
\left(c_{n i}-p_{n i i}\right) *\left[\frac{r_{n j}-p_{n j j}}{\sum_{j=1}^{k}\left(r_{n j}-p_{n j j}\right)}\right], & i \neq j
\end{array}\right.
$$

where $c_{n i}$ is the classified cover proportion of class $i$ in sampled pixel $n$ and $r_{n j}$ is the reference cover proportion of class $j$ in the pixel based on field measurements. $c_{n i}-p_{n i i}$ is the disagreement in pixel $n$ of a classification for class $i$, which denotes the commission proportion of the classification. Similarly, $r_{n j}-p_{n j j}$ is the disagreement in pixel $n$ of the reference map for class $j$, which denotes the omission proportion of the classification.

Each sampled pixel can be constructed an SCM; the final SCM is constructed by averaging the SCMs for all sampled pixels. The structure of the subconfusion matrix is similar to the confusion matrix calculated from hard classification classes. Taking three classes derived by LSMA as an example, the structure of the subconfusion matrix for three classes is given in Table II.

In Table II, the values of $P$ are expressed in percent. UA represents the proportion of commission errors, and PA represents the proportion of omission errors; UA and PA are calculated for
TABLE II

STRUCTURE OF THE SUbCONFUSION MATRIX FOR FRACTIONAL COVERS

\begin{tabular}{lcccccc}
\hline \hline & & \multicolumn{5}{c}{ Reference } \\
\cline { 3 - 7 } & & Class 1 & Class 2 & Class 3 & Row Total & UA \\
\hline Classification & Class 1 & $P_{11}$ & $P_{12}$ & $P_{13}$ & $C_{1}$ & $P_{11} / C_{1}$ \\
by LSMA & Class 2 & $P_{21}$ & $P_{22}$ & $P_{23}$ & $\mathrm{C}_{2}$ & $P_{22} / C_{2}$ \\
& Class 3 & $P_{31}$ & $P_{32}$ & $P_{33}$ & $C_{3}$ & $P_{33} / C_{3}$ \\
& Colum total & $R_{1}$ & $R_{2}$ & $R_{3}$ & 1 & \\
& pa & $P_{11} / R_{1}$ & $P_{22} / R_{2}$ & $P_{33} / R_{3}$ & & \\
\hline \hline
\end{tabular}

$\mathrm{OA}=\sum_{j=1}^{k} p_{j j}=P_{11}+P_{22}+P_{33}$, $\left.\left.c_{j}\right)\right] /\left[1-\sum_{j=1}^{k}\left(r_{j} * c_{j}\right)\right], k=3$.

$\kappa=\left[\sum_{j=1}^{k} p_{j j}-\sum_{j=1}^{k}\left(r_{j} *\right.\right.$

each class as

$$
\begin{aligned}
\mathrm{UA}_{j} & =p_{j j} / c_{j} \\
\mathrm{PA}_{j} & =p_{j j} / r_{j} .
\end{aligned}
$$

UA and PA are at category level, and the values of two indices are in the range $0-1$. A greater value denotes a higher classification accuracy of that class. On the other hand, OA and $\kappa$ are at the map level. The range of $\mathrm{OA}$ and $\kappa$ are also in the range $0-1$, with large values representing higher accuracy.

\section{Creation of Fractional ISA Categories}

In order to accurately analyze urban landscape patterns and quantify the impacts of ISA on the urban thermal environment, percent ISA was divided into discrete categories representing different levels of urban development. A range approach was used to group pixels based on fractional values of ISA. Each pixel was assigned to one of the ten equal ISA categories $(0 \%-10 \%, 10 \%-20 \%, 20 \%-30 \%, \ldots, 90 \%-100 \%)$. In general, the higher value of the percent ISA, the higher level of urbanization. Based on each ISA category, mean LST, mean percent ISA, mean FVC, areas of ISA, and vegetation cover can be calculated and analyzed. Grouping fractional covers in this manner facilitates an analysis of urban landscape pattern variations by ISA category and image date. The observed urban LST in each ISA category can be calculated, and the spatial patterns of the urban thermal environment can be analyzed for different urban densities. In this study, the area of percent ISA $>10 \%$ was defined as "urban area" and the area of 0\%-10\% ISA was defined as "rural area."

\section{E. Contributions of the Landscape Pattern in Each ISA Category to the Urban Thermal Environment}

Urbanization can increase LST by surface sealing from urban land encroachment into other landscapes that previously reduced the local LST [2], [47], [48]. However, each type of urban expansion pattern makes a different contribution to the process in different seasons [2]. In this study, we observed an increasing trend of UHI intensity with the urban expansion from 2001 to 2013. It is necessary to further explore the formation mechanisms of the thermal environment in different ISA categories with the urban expansion. It is inappropriate to directly compare 
LST values between different periods because the multitemporal imagery was acquired in different climatic conditions and different seasons. Therefore we used the average LST differences between the different urban development density areas and the entire urban area rather than absolute LST changes. The proportions of the area of research objects were calculated initially (i.e., the proportions of each ISA category area in urban area). Based on this information, we can estimate how changes in urban landscape pattern contributed to the change in entire urban LST. We then estimated the contribution of landscape pattern in each ISA category to the net increase or decrease in regional temperature dynamics. This analysis is valuable for spatially and temporally evaluating the contribution of each landscape to the UHI intensity.

In this study, the average LSTs of each ISA category and the entire urban area were calculated, and the contributions of the surface cover types to the urban thermal environment were estimated. The contribution index (CI) was calculated as follows:

$$
\mathrm{CI}=\mathrm{LST}_{\text {dif }} * S
$$

where CI is the contribution of the each ISA category to the regional LST, $\mathrm{LST}_{\text {dif }}$ is the average LST difference between the functional zone or the landscape and the entire area, and $S$ is the proportion of the area.

The area of the different ISA categories significantly affects the magnitude of the CI. If the role of each ISA category is determined, it will be helpful for finding ways to improve the thermal environment according to the spatial patterns within each ISA category.

\section{RESUltS AND DisCUSSION}

\section{A. Accuracy Analysis of the Subpixel Classes}

Using fractional covers derived from the high-resolution imagery as validation data, the accuracy of fractional covers derived by LSMA from Landsat imagery was analyzed. Similar to the confusion matrix for hard classification, subpixel confusion matrix calculated based on the fractional values was used to assess the accuracy for the subpixel values. Based on (7), the accuracy of each pixel can be constructed with a subconfusion matrix as in Table II. If many data points are used in calculating the tables of the subpixel confusion matrix, the computational steps become time intensive. Therefore, 25 sampled representative pixels shown in Fig. 4(a), with corresponding reference fractional data derived from high-resolution IKONOS and ZY-3 imagery, were, respectively, selected to construct 25 subpixel confusion matrices with fractional covers for accuracy assessment. The final subpixel confusion matrix was calculated by averaging the subpixel confusion matrices of the 25 sampled pixels. The accuracy of the 25 sampled pixels can represent the accuracy of the whole study area. The results are illustrated in the subpixel confusion matrices as in Tables III and IV.

In Tables III and IV, UA and PA were derived to analyze the accuracy of each endmember at category level. UA of ISA and vegetation are, respectively, $\geq 82.1 \%$ in Table III and $\geq 83.1 \%$
TABLE III

AVERAGE SUbCONFUSION MATRIX FOR THE ACCURACY ASSESSMENT OF THE FRACTIONAL COVERS EXTRACTED FROM ETM+ IMAGE IN 2001

\begin{tabular}{|c|c|c|c|c|c|c|}
\hline & \multicolumn{4}{|c|}{ Reference } & \multirow[b]{2}{*}{$\begin{array}{l}\text { Row } \\
\text { Total }\end{array}$} & \multirow[b]{2}{*}{ UA ( $\%)$} \\
\hline & & $\begin{array}{c}\text { Impervious } \\
\text { Surface }\end{array}$ & Vegetation & $\begin{array}{l}\text { Bare } \\
\text { Soil }\end{array}$ & & \\
\hline \multirow[t]{5}{*}{ Classification } & Impervious surface & 0.687 & 0.031 & 0.072 & 0.79 & 87.0 \\
\hline & Vegetation & 0.021 & 0.119 & 0.002 & 0.142 & 82.1 \\
\hline & Bare soil & 0.015 & 0.002 & 0.051 & 0.068 & 75.0 \\
\hline & Column total & 0.723 & 0.152 & 0.125 & 1 & \\
\hline & PA $(\%)$ & 95.0 & 78.3 & 40.8 & & \\
\hline
\end{tabular}

$\mathrm{OA}=0.857 ; \kappa=0.641$.

TABLE IV

AVERAGE SUbCONFUSION MATRIX FOR THE ACCURACY ASSESSMENT OF THE FractionAl COVERS EXTRACTED From OLI IMAGE IN 2013

\begin{tabular}{|c|c|c|c|c|c|c|}
\hline & \multicolumn{4}{|c|}{ Reference } & \multirow[b]{2}{*}{$\begin{array}{l}\text { Row } \\
\text { Total }\end{array}$} & \multirow[b]{2}{*}{ UA $(\%)$} \\
\hline & & $\begin{array}{c}\text { Impervious } \\
\text { Surface }\end{array}$ & Vegetation & $\begin{array}{l}\text { Bare } \\
\text { Soil }\end{array}$ & & \\
\hline \multirow[t]{5}{*}{ Classification } & Impervious surface & 0.699 & 0.036 & 0.051 & 0.786 & 88.9 \\
\hline & Vegetation & 0.026 & 0.133 & 0.001 & 0.16 & 83.1 \\
\hline & Bare soil & 0.009 & 0.002 & 0.043 & 0.054 & 79.6 \\
\hline & Column total & 0.734 & 0.171 & 0.095 & 1 & \\
\hline & PA $(\%)$ & 95.2 & 77.8 & 45.3 & & \\
\hline
\end{tabular}

$\mathrm{OA}=0.875 ; \kappa=0.680$.

in Table IV. PA of ISA and vegetation are, respectively, $\geq 78.3 \%$ in Table III and $\geq 77.8 \%$ in Table IV. Tables III and IV indicate a high classification accuracy of the two classes (percent ISA and percent vegetation) deviation and relatively little confusion with other classes. The accuracy of fractional bare soil deviation is the lowest in Tables III and IV. Spectral confusion resulted in misclassification and impacted the accuracy of fractional covers derivation. Tables III and IV show that spectral confusion resulted in misclassifying percent ISA, vegetation, and bare soil by the LSMA model, major confusion for ISA occurred with bare soil classes. The UA and PA of fractional bare soil are, 75.0\% and $40.8 \%$ for 2001 in Table III and, respectively, $79.6 \%$ and $45.3 \%$ for 2013 in Table IV. For fractional vegetation deviation, UA and PA are, respectively, $82.1 \%$ and $78.3 \%$ in Table III and $83.1 \%$ and $77.8 \%$ in Table IV, and the misclassification rates of vegetation were lower than those of bare soil. If the UA of one fractional cover is low, the probability that the other fractional cover types are incorrectly classified as this type (commission errors) is relatively high. And if the PA of one fractional cover is also low, this indicates that this fractional cover type has a high probability of being incorrectly classified as another type (omission errors). In this study, the UA and PA accuracies of fractional bare soil deviation were low, which impacted the overall accuracy of Tables III and IV.

Comparing the UA and PA of ISA and vegetation, in general, the accuracies of the fractional ISA and vegetation cover were slightly higher from Landsat 8 OLI image in 2013 (see Table IV) than for the fractional covers derived from ETM+ in 2001 (see 
TABLE V

Total Areas of ISA and Vegetation (KM²), Mean LST at EaCH Percent ISA Category of Urban AREa in 2001 and 2013

\begin{tabular}{|c|c|c|c|c|c|c|}
\hline \multicolumn{3}{|c|}{2001} & \multicolumn{4}{|c|}{2013} \\
\hline Percent ISA & Area of ISA & Area of Vegetation & Mean LST $(K)$ & Area of ISA & Area of Vegetation & Mean LST $(K)$ \\
\hline $10 \%-20 \%$ & 2.35 & 6.97 & 287.5 & 6.28 & 25.02 & 304.3 \\
\hline $20 \%-30 \%$ & 6.02 & 11.58 & 288.1 & 12.46 & 29.31 & 304.3 \\
\hline $30 \%-40 \%$ & 13.52 & 17.26 & 288.5 & 24.36 & 37.10 & 304.7 \\
\hline $40 \%-50 \%$ & 20.21 & 21.26 & 288.5 & 31.95 & 36.01 & 304.8 \\
\hline $50 \%-60 \%$ & 31.51 & 20.66 & 288.8 & 40.74 & 22.73 & 305.3 \\
\hline $60 \%-70 \%$ & 36.16 & 17.12 & 289.2 & 45.68 & 14.76 & 306.2 \\
\hline $70 \%-80 \%$ & 39.66 & 11.50 & 289.5 & 50.7 & 9.98 & 306.7 \\
\hline $80 \%-90 \%$ & 34.38 & 6.63 & 289.9 & 47.56 & 6.21 & 306.9 \\
\hline $90 \%-100 \%$ & 49.49 & 5.57 & 290.6 & 65.29 & 6.66 & 307.3 \\
\hline Total area & 233.3 & 118.55 & & 326.03 & 187.78 & \\
\hline
\end{tabular}

Table III). Table IV shows that bare soil spectra were also a source of confusion with ISA. As in Table III, ISA was partly confused with bare soil, and vice versa. The misclassification of these cover types degraded the accuracy of ISA, especially the bare soil. The main reason of the bare soil misclassification is that it is difficult to select bare soil endmembers to develop an optimal spectral library for spectral unmixing because the spectral characteristics of bare soil can be similar to those of bright ISA. Another type of class confusion was also found between dark vegetation impacted by shadow and dark ISA.

The oa and $\kappa$ were also calculated for fraction endmembers. Though UA or PA of some classes in Table III were higher than those in Table IV, the oa and $\kappa$ are 0.875 and 0.680 , respectively, in Table IV, higher than 0.857 and 0.641 in Table III. The comparison of Tables III and IV showed that fractional covers derived from the ETM+ image generally lead to more commission and omission errors than those derived from the OLI image. The accuracy of bare soil is low in Tables III and IV because we selected sample pixels of urban area for accuracy assessment. From Fig. 4(c) and (f), it is apparent that high fractional bare soil areas are located outside of the urban area, especially the areas alongside the river. If the sampled pixels in high fractional bare soil areas are selected, the accuracy of fractional bare soil will be higher. In general, considering the heterogeneity of the urban landscape pattern, the results showed that endmember fractions derived by LSMA model are a good representation of reality in the study area, and it is applicable to use subconfusion matrix to analyze the accuracy of subpixel fractional covers.

\section{B. Percent ISA Categories, FVC, and LST}

Fig. 4 shows that the $0 \%-10 \%$ ISA category is mainly located in the rural areas of the study area (fringe of the urban area) and the dominant landscape is forest. Obviously, this zone had the lowest level of urbanization among all the ISA categories. Urban land surface characteristics are primarily represented by impervious surface and pervious surface (especially the vegetation cover). In this study, the vegetation cover was calculated for all ISA categories with $>10 \%$ fractional cover to characterize the change of urban landscape patterns and further to analyze the urban thermal environment. The mean LST and the areas of ISA and vegetation were calculated for each urban
ISA category, as shown in Table V. Area covered by impervious surface/vegetation for each ISA category was calculated by summing the total fractional area of impervious surface/vegetation within that category. The area of impervious surface/vegetation in each pixel was calculated by multiplying the fractional value with the pixel area of $30 \times 30 \mathrm{~m}^{2}$, and then the total area was accumulated by the area of each pixel in each ISA category.

The nine urban ISA categories generally differed in land cover compositions (see Table V). The total area of urban ISA (233.3 $\mathrm{km}^{2}$ in $>10 \%$ ISA areas) in 2001 was less than that in $2013\left(326.03 \mathrm{~km}^{2}\right)$, which indicates significant urban landscape pattern changes resulting from urban expansion over this time period. Table $\mathrm{V}$ shows that the level of urbanization increased mainly in all the $>30 \%$ ISA categories, especially $80 \%-90 \%$ and $90 \%-100 \%$ ISA categories between 2001 and 2013. From 2001 to 2013, the areas of impervious surface, respectively, increased from 34.38 to $47.56 \mathrm{~km}^{2}$ for the $80 \%-90 \%$ ISA category and 49.49 to $65.29 \mathrm{~km}^{2}$ for the $90 \%-100 \%$ ISA category. Though the areas of ISA also increased for the $10 \%-20 \%$ and $20 \%-30 \%$ ISA categories between the two dates and rates of increase were higher, the increased area is relatively small. It was concluded that urban expansion and the changes of urban landscape patterns mainly occurred for the $>30 \%$ ISA categories between 2001 and 2013. Table V shows that the area of impervious surface increased by over $9 \mathrm{~km}^{2}$ for each $>30 \%$ ISA categories between the two dates.

ISA and vegetation cover vary remarkably between the core of the city and its periphery. ISA increases at the periphery of the city due to urban expansion. Table $\mathrm{V}$ indicates the concurrent changes of vegetation areas at different percent ISA categories at the two dates. Comparing the area of impervious surfaces between the two dates, the area of urban vegetation increased markedly in all the $10 \%-50 \%(10 \%-20 \%, 20 \%-30 \%$, $30 \%-40 \%$, and $40 \%-50 \%$ ) ISA categories. Table V also shows that the rate of increase of vegetation cover in all the 10\%-50\% ISA categories was higher than the ISA increase, suggesting that the urbanization during this period was accompanied with urban greening. Vegetation covered landscapes in urban areas were more interspersed with the various developed urban areas in 2013 in comparison to 2001 as a result of higher attention to urban greening as urban expansion continued. Because of urban expansion in the peri-urban vegetation area, the vegetation 
TABLE VI

Transition Matrix of ISA Change For EACH Discrete ISA CATEGORY IN FUZHOU BETwEen 2001 AND 2013 (KM²)

\begin{tabular}{|c|c|c|c|c|c|c|c|c|c|c|}
\hline 2001 & $20130 \%-10 \%$ & $10 \%-20 \%$ & $20 \%-30 \%$ & $30 \%-40 \%$ & $40 \%-50 \%$ & $50 \%-60 \%$ & $60 \%-70 \%$ & $70 \%-80 \%$ & $80 \%-90 \%$ & $90 \%-100 \%$ \\
\hline $0 \%-10 \%$ & 0.55 & 2.32 & 3.6 & 6.15 & 6.51 & 4.72 & 4.04 & 5.44 & 4.34 & 5.75 \\
\hline $10 \%-20 \%$ & 0.05 & 2.35 & 0.30 & 0.31 & 0.42 & 0.43 & 0.37 & 0.49 & 0.42 & 0.92 \\
\hline $20 \%-30 \%$ & 0.07 & 0.30 & 6.02 & 0.82 & 0.84 & 0.61 & 0.33 & 0.63 & 0.85 & 0.61 \\
\hline $30 \%-40 \%$ & 0.09 & 0.28 & 0.64 & 13.52 & 1.13 & 0.84 & 0.76 & 1.01 & 1.30 & 1.18 \\
\hline $40 \%-50 \%$ & 0.08 & 0.27 & 0.52 & 1.15 & 20.21 & 1.01 & 1.06 & 0.91 & 0.98 & 0.97 \\
\hline $50 \%-60 \%$ & 0.07 & 0.24 & 0.63 & 1.01 & 0.86 & 31.51 & 0.80 & 0.82 & 1.25 & 1.39 \\
\hline $60 \%-70 \%$ & 0.04 & 0.22 & 0.33 & 0.79 & 0.64 & 0.32 & 36.16 & 0.61 & 1.02 & 1.48 \\
\hline $70 \%-80 \%$ & 0.03 & 0.14 & 0.21 & 0.32 & 0.48 & 0.65 & 0.86 & 39.66 & 2.13 & 1.71 \\
\hline $80 \%-90 \%$ & 0.02 & 0.10 & 0.13 & 0.19 & 0.57 & 0.43 & 0.90 & 0.59 & 34.38 & 1.79 \\
\hline $90 \%-100 \%$ & 0.01 & 0.06 & 0.08 & 0.10 & 0.29 & 0.22 & 0.40 & 0.54 & 0.89 & 49.49 \\
\hline Total area & 1.01 & 6.28 & 12.46 & 24.36 & 31.95 & 40.74 & 45.68 & 50.7 & 47.56 & 65.29 \\
\hline
\end{tabular}

area in the $0 \%-10 \%$ ISA categories in 2001 were replaced by ISA in the $10 \%-20 \%, 20 \%-30 \%, 30 \%-40 \%$, and $40 \%-50 \%$ ISA categories in 2013. Fig. 3 also shows this trend. However, in the $60 \%-70 \%, 70-\%-80 \%$, and $80 \%-90 \%$ ISA categories, vegetation slightly decreased as ISA slightly increased with the urban expansion in this period. Table V shows that the greatest increase in ISA occurred in the $90 \%-100 \%$ ISA zone, from $49.49 \mathrm{~km}^{2}$ in 2001 to $65.29 \mathrm{~km}^{2}$ in 2013, indicating that high density urban development was the main mode of urbanization during this time period.

ISA and vegetation are the two primary urban land cover types. At the pixel scale, LST increases as coverage of ISA expands and decreases as the vegetation coverage increases. Concerning the mean LST in each ISA category in Table V, the highest mean LST is $290.6 \mathrm{~K}$ in the $90 \%-100 \%$ ISA category in 2001. However, the $90 \%-100 \%$ ISA category had a higher mean LST of $307.3 \mathrm{~K}$ for 2013. Comparing the LST between two dates, the LST at each ISA category in 2001 are less than the LST in any ISA category in 2013. Though urban expansion and urban landscape pattern change impacted the LST, the main reason for this difference is caused by the seasonal variations. In general, the mean LST in each ISA category in the summer of 2013 was about $17-18 \mathrm{~K}$ higher than in early spring 2001. Measuring LST and FVC for different fractional impervious surface provides a precise characterization of the urban landscape and LST patterns and is useful for urban ecological planning.

\section{ISA Variations Within Discrete ISA Categories}

Subpixel fractional covers can reveal not only the spatial structure of urban landscape patterns but also the change patterns of within-class change [11]. In some urban areas, minor land cover change may be taking place at the subpixel scale but would not be detectable at the pixel scale using hard classification approaches. In this study, the area of impervious surfaces within each ISA category was calculated for two dates and the area changing from one ISA category to another was also quantified between 2001 and 2013. A transition matrix of ISA change based on each percent ISA category was constructed and is shown in Table VI.
In the study area, natural landscape patterns in the $0 \%-10 \%$ ISA category are characterized by low ISA but high FVC. Table VI shows that the $0 \%-10 \%$ ISA category was the main landscape type that saw a sharp increase of surface sealing in this period. Because of urban expansion, out of the $0-10 \%$ ISA category, $2.32 \mathrm{~km}^{2}$ changed to $10-20 \%$ between 2001 and $2013,3.6 \mathrm{~km}^{2}$ changed to $20-30 \%$ ISA, $6.15 \mathrm{~km}^{2}$ to $30-40 \%$ ISA, $6.51 \mathrm{~km}^{2}$ to $40-50 \%$ ISA, 4.72 to $50-60 \%$ ISA, 4.04 $\mathrm{km}^{2}$ to $60-70 \%$ ISA, $5.44 \mathrm{~km}^{2}$ to $70-80 \%$ ISA, $4.34 \mathrm{~km}^{2}$ to $80-90 \%$ ISA and $5.75 \mathrm{~km}^{2}$ to $90-100 \%$ ISA, respectively (Table VI.). Over the same period, landscape pattern change between other ISA categories (10\%-100\% ISA categories, urban area) was relatively low compared to the landscape pattern change in the $0 \%-10 \%$ ISA category. For the urban area, ISA in the $30 \%-40 \%$ and $40 \%-50 \%$ ISA categories, respectively, increased to $>40 \%$ and $>50 \%$ ISA categories and were larger than the increase of ISA in the 50\%-60\%, 60\%-70\%, $70 \%-80 \%$, and $80 \%-90 \%$ to other urban ISA categories. Obviously, urban landscape patterns at 90\%-100\% ISA in 2001 had nearly no urbanization.

The increased urbanization during this time period was accompanied with urban greening in some ISA categories since 2001. This was proved by the transfer matrix in Table VI. Taking an example of the $40 \%-50 \%$ ISA category, from 2001 to 2013 about 1.01, 1.06, 0.91, 0.98, and 0.97 $\mathrm{km}^{2}$ ISA were, respectively, transferred from the $40 \%-50 \%$ ISA category to the $50 \%-60 \%, 60 \%-70 \%, 70 \%-80 \%$, $80 \%-90 \%$, and $90 \%-100 \%$ ISA categories. In the same period, about $1.15,0.52,0.27$, and $0.08 \mathrm{~km}^{2}$ ISA, respectively, were transferred from the $40 \%-50 \%$ ISA category to the $30 \%-40 \%, 20 \%-30 \%, 10 \%-20 \%$, and $0 \%-10 \%$ ISA categories. The reason for these transitions is that vegetationcovered landscapes in urban areas were more interspersed with the various developed urban areas in 2013 in comparison to 2001 as a result of urban greening as urban expansion continued. With a greater attention to ecological planning, more vegetation was planted in some areas such as residential areas and roadsides post 2001 , which resulted in slightly reducing the $40 \%-50 \%$ ISA category to $30 \%-40 \%, 20 \%-30 \%, 10 \%-20 \%$, and $0 \%-10 \%$ ISA categories. Other ISA categories can also be analyzed as done here for the $40 \%-50 \%$ ISA category. 
TABLE VII

CONTRIBUtion of URBAn LANDSCAPE PATTERnS IN DifFERENT ISA CATEGORIES TO THE URBAN THERMAL ENVIRONMENT

\begin{tabular}{|c|c|c|c|c|c|c|c|c|c|}
\hline \multirow[t]{2}{*}{ Year } & \multicolumn{9}{|c|}{ Urban Landscapes Based on Percent ISA } \\
\hline & $10 \%-20 \%$ & $20 \%-30 \%$ & $30 \%-40 \%$ & $40 \%-50 \%$ & $50 \%-60 \%$ & $60 \%-70 \%$ & $70 \%-80 \%$ & $80 \%-90 \%$ & $90 \%-100 \%$ \\
\hline 2001 & $-6.29 \%$ & $-6.56 \%$ & $-6.32 \%$ & $-8.51 \%$ & $-5.18 \%$ & $0.67 \%$ & $4.69 \%$ & $8.14 \%$ & $19.38 \%$ \\
\hline 2013 & $-10.38 \%$ & $-13.02 \%$ & $-12.44 \%$ & $-12.13 \%$ & $-4.43 \%$ & $5.32 \%$ & $10.1 \%$ & $10.8 \%$ & $26.17 \%$ \\
\hline
\end{tabular}

From Table VI, we conclude that urbanization mainly occurred in the $0 \%-10 \%$ ISA category from 2001 to 2013. The urbanization mainly encroached on the fringes of the city and the landscape patterns were changed from non-ISA to ISA with urban expansion. Fig. 4 shows that the extent of the urban area in 2013 is larger than in 2001, especially in the eastern, southern, and western parts of the city. Compared to the landscape pattern change in the $0 \%-10 \%$ ISA category, the changes of landscape patterns between other urban ISA categories are relatively small, especially for the 10\%-20\% ISA and $20 \%-30 \%$ ISA categories. With the extent of ISA category expansion, urban greening can slightly decrease small parts of the high ISA category to a low percent ISA category (see Table VI). Though the ISA extent has not changed at pixel scale, the vegetation weaved into the urban fabric decreases the ISA category. The analysis of the landscape structure for each ISA category is helpful to explore the climate adaptation potential of different ISA categories. Though fractional cover derived by LSMA is subject to some error sources and the accuracy of fractional cover derivation impacted the analysis of urban landscape patterns, general change trends can be observed in Table VI.

\section{Contribution of Each ISA Category to the Urban Thermal Environment}

ISA encroaching onto other landscapes contributes to a relative LST increase and impacts on the thermal environment. Due to the seasonal variability and imaging under different atmospheric conditions, it is inappropriate to directly compare urban LST values between two dates, even in the same region. However, each type of urban landscape pattern in different regions and even in different seasons may make a different contribution to the thermal environment. Analyzing the contribution of urban landscape patterns to the urban thermal environment will inform urban planning and urban adaptation to the impacts of climate change on cities.

In this study, we analyzed the contributions of different ISA categories to the urban thermal environment with the urban expansion between 2001 and 2013 (see Table VII). The contribution of each urban ISA category to the entire urban thermal environment net increase or decrease, were estimated in (10). The thermal environment CI was defined as the mean LST difference multiplied by the proportion of the area. The mean LST of each urban ISA category and the entire urban area $(\geq 10 \%$ ISA area) were calculated in Table V for 2001 and 2013, and the estimated $\mathrm{LST}_{\text {dif }}$ is the difference between the mean LST of each ISA category to the mean LST of the entire urban area. The proportion of the area was calculated by dividing the area of each ISA category with the area of the entire urban ISA categories ( $\geq 10 \%$ ISA). In the study area, the mean LST in the $\geq 10 \%$ ISA area was $289.15 \mathrm{~K}$ in 2001 and $305.69 \mathrm{~K}$ in 2013 . The CI is positive with regard to the ISA categories with the mean LST above the mean LST of the entire urban area, and is negative with regard to the ISA categories with the mean LST below the mean LST of the entire urban area. However, the proportion of the area of each urban ISA category and the area of the entire urban ISA categories also affect the magnitude of the CI.

As shown in Table VII, the $<60 \%$ ISA categories had negative contributions to the urban thermal environment. However, the negative contributions of the $10 \%-20 \%, 20 \%-30 \%$, $30 \%-40 \%$, and $40 \%-50 \%$ ISA categories changed significantly between the two dates in accordance with the increase of ISA and vegetation (see Table V). One reason is that the urban expansion with urban landscape pattern change impacted the urban LST. In the ISA categories $<60 \%$, the rates of increase of vegetation were higher than the increase in ISA within each class might lead one to expect. Another important reason is the impact of seasonal variations. The cooling effect is obvious for the vegetation in the urban ISA categories in summer, whereas the cooling effect was stronger in summer 2013 than in spring 2001. Therefore, the negative contributions were larger in summer than in spring in the $10 \%-20 \%, 20 \%-30 \%, 30 \%-40 \%$, and $40 \%-50 \%$ ISA categories. Because the urban expansion resulted in an area change inside each ISA category and seasonal variations impacted the LST difference, the negative contribution was largest in the 40\%-50\% ISA category in 2001 and the $20 \%-30 \%$ ISA category in 2013 . For the $50 \%-60 \%$ ISA category, because the ISA extent and vegetation cover extent changed little between the two dates and the mean LST at this category were also close to the mean LST of urban area, the contribution to the urban thermal environment changed only a little.

The $90 \%-100 \%$ ISA category had the highest LST in the early spring of 2001 and the summer of 2013 and contributed most to the urban thermal environment at both dates. In particular, the $90 \%-100 \%$ ISA category made a larger contribution to the urban thermal environment in the summer of 2013 than in the spring of 2001. The contributions were $19.38 \%$ in the early spring of 2001 and $26.17 \%$ in the summer of 2013 . The positive contributions of the $60 \%-70 \%, 70 \%-80 \%, 80 \%-90 \%$, and $90 \%-100 \%$ ISA categories increased significantly between the two dates in accordance with the observed increase in ISA and decrease in vegetation cover in the $60 \%-70 \%, 70 \%-80 \%$, 
and $80 \%-90 \%$ ISA categories, and the large increase in ISA with a small increase in vegetation in the $90 \%-100 \%$ ISA category. Contrary to the impacts of vegetation growth on LST, an ISA expansion increases LST. Urban land of the $>60 \%$ ISA categories were the main contributor of heat to the regional thermal environment in the different seasons, especially in summer. The average LST of high density urban land was higher than the average urban LST. The reason is that these areas have dense buildings and little vegetation, the surface heat release efficiency is reduced because of reflection and absorption by the urban canopy, and there is less energy loss due to latent heat fluxes from evaporation from impervious urban surfaces. In addition, anthropogenic heat sources are strong in this region. These reasons explain why there is greater heat storage in urban surfaces.

As shown by this analysis, the urban expansion resulted in urban landscape pattern change and impacted the contribution of each ISA category to the urban thermal environment. Seasonal variations also had significant impacts on the contributions to the thermal environment. A comparison of the two dates in Table VII shows that the positive/negative contributions of urban land to the thermal environment were generally smaller in spring 2001 than in summer 2013. Through the analysis of regional contributions to the urban thermal environment, the role of each ISA category was determined in different seasons. The $>60 \%$ ISA categories were notable for their positive contributions to the urban thermal environment, while the $<60 \%$ ISA categories made negative contributions that lowered the LST. It is necessary to further explore the formation mechanisms of the thermal environment in these ISA categories. The vegetation in ISA categories as a cooling source must be protected in future urban development. The cooling mechanism in each category should also be further analyzed to find ways to improve the thermal environment in specific ISA categories and the entire urban area.

\section{CONCLUSION}

Urbanization can trigger local LST increases resulting from the process of urban land encroaching into other landscapes. However, each urban landscape pattern in different regions and in different seasons makes a different contribution to the process. This study used a subpixel confusion matrix to evaluate the accuracy of subpixel fractional land cover types extracted by LSMA, and used a CI to evaluate the contributions of different ISA categories to the urban thermal environment. The mean differences of LST between each ISA category and the entire urban area, and the proportions of the area of each ISA category were calculated to estimate the contribution of each ISA category to the urban thermal environment at two image acquisition dates. The results showed that the $>60 \%$ ISA categories enhanced LST and the $<60 \%$ ISA categories cooled the urban thermal environment in Fuzhou. Though urban landscape pattern change impacted the contributions of each ISA category to the urban thermal environment, seasonal variations also had significant impacts on the thermal environment. The positive/negative contributions of urban ISA categories to the urban thermal environment are smaller in early spring than in summer. The results can provide useful information for urban planning and urban adaptation to the impacts of climate change.

In the study, the ISA category approach has been used to analyze the spatial patterns of specific ISA ranges and their impacts on the thermal environment of the entire urban area. Each ISA category plays a different role in the urban thermal environment because of different landscape patterns. The variations of mean $\%$ ISA coverage were very small within the ISA categories at the two dates. This can minimize the variations of landscape patterns in small ISA categories at different dates. The impact of the variations of landscape patterns on mean LST values of each ISA category between different dates was small. Therefore, the seasonal impacts of each urban landscape pattern type in each ISA category on the urban thermal environment can be further quantified by comparing the mean LST in the same low ISA categories. This can help to quantitatively characterize the spatial patterns of urban LST and provide useful information for urban ecological design and planning.

The seasonal variation and the urban landscape pattern change impact on LST and were analyzed based on discrete ISA categories (urban development density areas). The results showed that the seasonal impact on urban LST was about $17-18 \mathrm{~K}$ between summer and early spring, and the impact of urban landscape pattern changes on LST was about $3 \mathrm{~K}$ in the urban area between the two dates. In this study, the major fluctuations of mean LST in each low ISA category between the two dates were mainly caused by seasonal variation.

The accuracy assessment for hard classifications commonly uses an error matrix (confusion matrix), comparing a sample of reference data and corresponding land cover types extracted from the hard classification. Considering the lack of widely accepted measures for accuracy assessment of a soft classification, in this study, a subpixel confusion matrix was used to assess the accuracy by comparing the fractional cover of each urban land cover type extracted by LSMA with corresponding reference fractional data derived from high-resolution imagery. Each sampled pixel can be used to construct a subpixel confusion matrix with the reference data. The final subpixel confusion matrix is built by averaging the subpixel confusion matrices for all sampled pixels. The results showed that the methodology is reasonable for assessing the accuracy of soft classification in heterogeneous urban areas at map and category levels.

In spite of the merits of this study, one of its limitations is the lack of a highly accurate estimation of the impact of the variation of ISA on LST. Though the impacts of the variations of fractional ISA cover in each ISA category between the two dates were minor and can be neglected, it impacted the estimation of the seasonal variations in LST in each ISA category. Fractional cover estimation by spectral unmixing is very important for urban landscape pattern and thermal environment analysis. Chen et al. [46] and van der Meer et al. [49] have pointed out that if the endmember spectra are highly correlated, the inversion of spectral unmixing becomes unstable. Because our focus in this study is to analyze urban land cover and thermal patterns, we did not analyze this. In the future, the impacts of the spectral correlation between different endmembers need to be quantified 
to assess their impacts on the accuracy of fractional cover estimation. In addition, the cooling mechanism of the vegetation in each ISA category should be further analyzed to find ways to improve the thermal environment in cities.

Fractional cover data with continuous values can reveal the spatial structure of urban landscape patterns and within-class change. Clarification as to how changes in the coverage of ISA and vegetation cover contribute to variations in urban LST is necessary in order to mitigate the UHI effect and enable urban areas to effectively adapt to climate change. In future, mean FVC can be estimated within each ISA category, and the variations of mean FVC can be analyzed based on variations of fractional ISA cover. Through quantifying the LST with fractional variation of impervious surface and vegetation cover based on discrete ISA categories, this study provides a precise characterization of land cover and LST patterns for urban ecological planning.

\section{ACKNOWLEDGMENT}

The authors would like to thank four anonymous reviewers for constructive comments.

\section{REFERENCES}

[1] T. W. Owen, T. N. Carlson, and R. R. Gillies, "An assessment of satellite remotely sensed land cover parameters in quantitatively describing the climatic effect of urbanization," Int. J. Remote Sens., vol. 19, pp. $1663-$ $1681,1998$.

[2] X. L. Chen, M. Z. Zhao, P. X. Li, and Z. Y. Yin, "Remote sensing imagebased analysis of the relationship between urban heat island and land use/cover changes," Remote Sens. Environ., vol. 104, pp. 133-146, 2006.

[3] E. G. McPherson et al., "Quantifying urban forest structure, function, and value, The Chicago Urban Forest Climate Project," Urban Ecosyst., vol. 1, pp. 49-61, 1997.

[4] G. Xian and M. Crane, "An analysis of urban thermal characteristics and associated land cover in tampa bay and las vegas using landsat satellite data," Remote Sens. Environ., vol. 104, pp. 147-156, 2006.

[5] J. A. Voogt and T. R. Oke, "Thermal remote sensing of urban climates," Remote Sens. Environ., vol. 86, pp. 370-84, 2003.

[6] R. Pu, P. Gong, M. Ryo, and S. Todashi, "Assessment of multi-resolution and multi-sensor data for urban surface temperature retrieval," Remote Sens. Environ., vol. 104, pp. 211-225, 2006.

[7] B. Dousset and F. Gourmelon, "Satellite multi-sensor data analysis of urban surface temperatures and land cover," ISPRS J. Photogrammetry Remote Sens., vol. 58, pp. 43-54, 2003.

[8] Q. Weng, D. Lu, and J. Schubring, "Estimation of land surface temperature-vegetation abundance relationship for urban heat island studies," Remote Sens. Environ., vol. 89, pp. 467-483, 2004.

[9] A. Buyantuyev and J. Wu, "Urban heat islands and landscape heterogeneity: Linking spatiotemporal variations in surface temperature to land-cover and socioeconomic patterns," Landscape Ecol., vol. 25, pp. 17-33, 2010.

[10] C. E. Woodcock and A. H. Strahler, "The factor of scale in remote sensing," Remote Sens. Environ., vol. 21, pp. 311-22, 1987.

[11] Y. Zhang, I. Odeh, and C. Han, "Bi-temporal characterization of land surface temperature in relation to impervious surface area, NDVI and NDBI, using a sub-pixel image analysis," Int. J. Appl. Earth Observation Geoinform., vol. 11, pp. 256-264, 2009.

[12] X. Chen, H. Sun, H. Yang, Z. Zhang, "Urban spatial growth analysis from satellite-derived imperviousness in an oasis city," in Proc. 2nd Conf. Environ. Sci. Inf. Appl. Technol., 2010, pp. 1: 517-520.

[13] D. Lu and Q. Weng, "Use of impervious surface in urban land-use classification," Remote Sens. Environ., vol. 102, pp. 146-160, 2006.

[14] A. E. Frazier and L. Wang, "Characterizing spatial patterns of invasive species using sub-pixel classifications," Remote Sens. Environ., vol. 115, pp. 1997-2007, 2011.

[15] Q. Weng, "Remote sensing of impervious surfaces in the urban areas: Requirements, methods, and trends," Remote Sens. Environ., vol. 117, pp. 34-49, 2012.
[16] C. L. Arnold, Jr., and C. J. Gibbons, "Impervious surface coverage the emergence of a key environmental indicator," J. Amer. Planning Assoc., vol. 62 , no. 2, pp. 243-258, 1996.

[17] Y. Zhang, I. Odeh, and E. Ramadan, "Assessment of land surface temperature in relation to landscape metrics and fractional vegetation cover in an urban/peri-urban region using Landsat data," Int. J. Remote Sens., vol. 34 no. 1, pp. 168-189, 2013.

[18] M. O. Smith, S. L. Ustin, J. B. Adams, and A. R. Gillespie, "Vegetation in deserts: I. A regional measure of abundance from multispectral images," Remote Sens. Environ., vol. 31, no. 1, pp. 1-26, 1990.

[19] T. Rashed, "Remote sensing of within-class change in urban neighborhood structures," Comput., Environ. Urban Syst., vol. 32, pp. 343-354, 2008.

[20] R. Michishita, Z. Jiang, and B. Xu, "Monitoring two decades of urbanization in the Poyang Lake Area, China through spectral unmixing," Remote Sens. Environ., vol. 117, pp. 3-18, 2012.

[21] R. G. Congalton, "A review of assessing the accuracy of classifications of remotely sensed data," Remote Sens. Environ., vol. 37, no. 11, pp. 35-46, 1991.

[22] E. Binaghi, P. A. Brivio, P. Ghezzi, and A. Rampini, "A fuzzy set-based accuracy assessment of soft classification," Pattern Recognit. Lett., vol. 20 no. 9, pp. 935-948, 1999.

[23] J. Chen, X. Zhu, H. Imura, and X. Chen, "Consistency of accuracy assessment indices for soft classification: Simulation analysis," ISPRS J. Photogrammetry Remote Sens., vol. 65, pp. 156-164, 2010.

[24] X. Cao, A. Onishi, J. Chen, and H. Imura, "Quantifying the cool island intensity of urban parks using ASTER and IKONOS data," Landscape Urban Planning, vol. 96, pp. 224-231, 2010.

[25] L. Klok, S. Zwart, H. Verhagen, and E. Mauri, "The surface heat island of Rotterdam and its relationship with urban surface characteristics," Res. Conserv. Recycling, vol. 64, pp. 23-29, 2012.

[26] R. R. Gillies and T. N. Carlson, "Thermal remote sensing of surface soil water content with partial vegetation cover for incorporation into climate models," J. Appl. Meteorol., vol. 34, pp. 745-756, 1995.

[27] F. Yuan and M. E. Bauer, "Comparison of impervious surface area and normalized difference vegetation index as indicators of surface urban heat island effects in Landsat imagery," Remote Sens. Environ., vol. 106 , pp. 375-386, 2007.

[28] T. A. Schroeder, W. B. Cohen, C. H. Song, M. J. Canty, and Z. Q. Yang, "Radiometric correction of multi-temporal Landsat data for characterization of early successional forest patterns in western Oregon," Remote Sens. Environ., vol. 103, pp. 16-26, 2006.

[29] A. Berk, G. P. Anderson, P. K. Acharya et al., MODTRAN4 User's Manual, Air Force Research Laboratory, Ontar Corporation, North Andover, MA, USA, pp. 10-35, 1999.

[30] J. A. Barsi, J. R. Schott, F. D. Palluconi, and S. J. Hook, "Validation of a web-based atmospheric correction tool for single thermal band instruments," Proc. SPIE, vol. 5882, Bellingham, WA. 7, 2005.

[31] A. A. Van De Grienzd and M. Owe, "On the relationship between thermal emissivity and the normalized difference vegetation index for nature surfaces," Int. J. Remote Sens., vol. 14, no. 6, pp. 1119-1131, 1993.

[32] J. A. Sobrino, N. Raissouni, and Z. L. Li, "A comparative study of land surface emissivity retrieval from NOAA data," Remote Sens. Environ. vol. 75, pp. 256-266, 2001.

[33] G. Chander and B. Markham, "Revised Landsat-5 TM radiometric calibration procedures and post calibration dynamic ranges," IEEE Trans. Geosci. Remote Sens., vol. 41(11), pp. 2674-2677, 2003.

[34] J. B. Adams, D. E. Sabol, V. Kapos, R. A. Filho, D. A. Roberts, M. O. Smith et al., "Classification of multispectral images based on fractions of endmembers: Application to land cover change in the Brazilian Amazon," Remote Sens. Environ., vol. 52, pp. 137-154, 1995.

[35] J. F. Mustard and J. M. Sunshine, "Spectral analysis for earth science: Investigations using remote sensing data," in Remote Sensing for the Earth Sciences: Manual of Remote Sensing A. N. Rencz, Ed., 3rd ed. New York, NY, USA: Wiley, 1999, vol. 3, pp. 251-307.

[36] Z. Mitraka, N. Chrysoulakis, Y. Kamarianakis, P. Partsinevelos, and A. Tsouchlaraki, "Improving the estimation of urban surface emissivity based on sub-pixel classification of high resolution satellite imagery," Remote Sens. Environ., vol. 117, pp. 125-134, 2012.

[37] S. Tompkins, J. F. Mustard, C. M. Pieters, and D. W. Forsyth, "Optimization of endmembers for spectral mixture analysis," Remote Sens. Environ., vol. 59, pp. 472-489, 1997.

[38] A. J. Elmore, J. F. Mustard, S. J. Manning, and D. B. Lobell, "Quantifying vegetation change in semiarid environments: Precision 
and accuracy of spectral mixture analysis and the normalized difference vegetation index," Remote Sens. Environ., vol. 73, pp. 87-102, 2000.

[39] C. Wu and A. T. Murray, "Estimating impervious surface distribution by spectral mixture analysis," Remote Sens. Environ., vol. 84, pp. 493-505, 2003.

[40] M. K. Ridd, "Exploring a V-I-S (vegetation-impervious surface-soil) model for urban ecosystem analysis through remote sensing: Comparative anatomy for cities," Int. J. Remote Sens., vol. 16, pp. 2165-2185, 1995.

[41] R. S. Lunette, "Applications, project formulation, and analytical approach," in Remote Sensing Changing Detection: Environmental Monitoring Methods and Applications, R. S. Lunetta and C. D. Elvidge, Eds. London, U.K.: Taylor \& Francis, 1998, pp. 1-19.

[42] J. W. Boardman, F. A. Kruse, and R. O. Green, "Mapping target signatures via partial unmixing of AVIRIS data," in Proc. Summaries of the 5th Annual JPL Airborne Geosci. Workshop. Pasadena, CA, USA: Jet Propulsion Laboratory Publications, 1995, pp. 23-26.

[43] Q. Weng, "Thermal infrared remote sensing for urban climate and environmental studies: Methods, applications, and trends," ISPRS J. Photogrammetry Remote Sens., vol. 64, pp. 335-344, 2009.

[44] G. M. Foody, "Approaches for the production and evaluation of fuzzy land cover classifications from remotely-sensed data," Int. J. Remote Sens., vol. 17, no. 7, pp. 1317-1340, 1996.

[45] R. G. Pontius and M. L. Cheuk, "A generalized cross-tabulation matrix to compare soft-classified maps at multiple resolutions," Int. J. Geographical Inf. Sci., vol. 20, no. 1, pp. 1-30, 2006.

[46] X. Chen, J. Chen, X. Jia, and J. Wu, "Impact of collinearity on linear and nonlinear spectral mixture analysis," in Proc. 2nd Workshop Hyperspectral Image Signal Processing (WHISPERS): Evolution Remote Sensing, 2010, pp. $1-4$.

[47] K. Trusilova, M. Jung, G. Churkina, U. Karstens, M. Heimann, and M. Claussen, "Urbanization impacts on the climate in Europe: Numerical experiments by the PSU-NCAR mesoscale model (MM5)," J. Appl. Meteorol. Climatol., vol. 47, no. 5, pp. 1442-1455, 2008.

[48] S. Xu, "An approach to analyzing the intensity of the daytime surface urban heat island effect at a local scale," Environ. Monitoring Assessment, vol. 151, no. 1-4, pp. 289-300, 2009.

[49] F. D. van der Meer and X. P. Jia, "Collinearity and orthogonality of endmembers in linear spectral unmixing," Int. J. Appl. Earth Observation Geoinform., vol. 18, pp. 491-503, 2012.

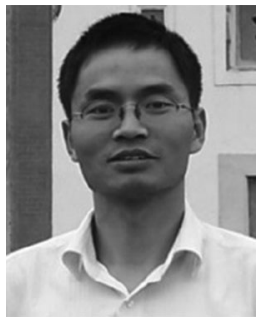

Youshui Zhang received the Ph.D. degree from Nanjing University, Nanjing, China, in 2004.

$\mathrm{He}$ is currently a Professor at the College of Geography, Fujian Normal University, Fuzhou, China. His current research interests include urban thermal infrared remote sensing for the climate adaptation potential of cities and remote sensing for natural resources and environment. In 2009, he was supported by Australia Endeavour Research Fellowship to do research at the University of Sydney, Australia. In the period of 2013-2014, he was also supported by China Scholarship Council to do research as a visiting scholar at the University of Manchester, U.K.

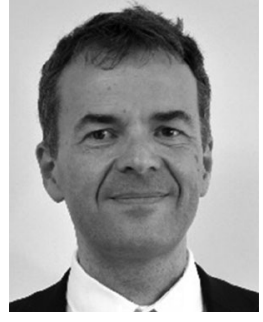

Heiko Balzter was received the Dipl.Ing.agr. degree and the Dr.agr. degree from Justus-Liebig University, Giessen, Germany, in 1994 and 1998, respectively.

$\mathrm{He}$ is currently Director of the Centre for Landscape and Climate Research in the Leicester Institute for Space and Earth Observation, University of Leicester, Leicester, U.K., and a Member of the NERC National Centre for Earth Observation. Before joining the University he was Head of Section for Earth Observation in the Centre for Ecology and Hydrology, Monks Wood, U.K., where from 1998 to 2006. His current research interests include interactions between earth observation of ecosystems and the processes that affect their dynamics, across multiple spatial and temporal scales, climate change and land use change impacts on the provision of ecosystem services, and the effects of spatial patterns and processes on biological populations in evolving, three-dimensional landscapes. He has extensive expertise in Earth observation and remote sensing of the land surface, particularly of forests, and lakes.

Prof. Balzter holds the Royal Society Wolfson Research Merit Award (2011) and the Royal Geographical Society's Cuthbert Peek Award "for advancing geographical knowledge of human impact through earth observation" (2015). He is a Member of the Group on Earth Observations (GEO) Programme Board, the Steering Committee of the NERC Airborne Remote Sensing Facility, and the AIRSAR Steering Board for the Satellite Applications Catapult and Airbus Defence and Space.

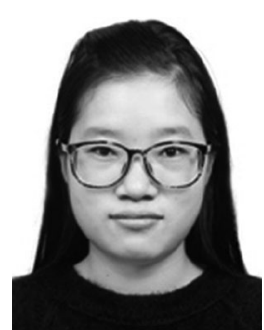

Bin Liu is currently working toward the Master's degree in cartography and geographic information system at Fujian Normal University, Fuzhou, China.

Her current research interests include urban thermal infrared remote sensing for the climate adaptation potential of cities and remote sensing geological analysis and calculation.

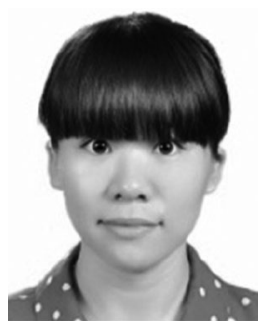

Yajun Chen is currently working toward the Master's degree in cartography and geographic information system at Fujian Normal University, Fuzhou, China.

Her current research interests include vegetation hyperspectral remote sensing and remote sensing applications for environmental monitoring. 